\title{
Business Interoperability Profiles: Relating Business Interoperability Issues To Technical Interoperability Solutions
}

\author{
Ulrike Greiner ${ }^{1}$, Christine Legner ${ }^{2}$, Sonia Lippe ${ }^{1}$, Kristin Wende ${ }^{2}$ \\ SAP Research, Karlsruhe (Germany) / Brisbane (Australia) \\ \{ulrike.greiner, sonia.lippe\}@sap.com \\ 2 IWI, University of St. Gallen, St. Gallen (Switzerland) \\ \{christine.legner, kristin.wende\}@unisg.ch
}

\begin{abstract}
The emerging field of interoperability research has come up with a vast number of concepts and technical solutions. However, until today, those technical interoperability solutions are not yet sufficiently linked to the business problems they address. This paper systemizes typical interoperability issues from a business perspective (described by seven Business Interoperability Profiles) and identifies appropriate interoperability solutions which may solve these issues. It extends previous interoperability research by linking the technical view on interoperability to business drivers and needs.
\end{abstract}

\section{Introduction}

In today's economy, enterprises realise networked business models with the goal to better serve their customers and to produce products and services more efficiently. They form temporary or permanent collaborations and pool resources, capabilities, and information. However, the vision of independent enterprises working together as an entirely virtual organisation has not yet become reality. Companies find it very time-consuming and costly to establish electronic business relationships with a larger number of business partners. Insufficient interoperability is a major impediment. In order to address these issues, the emerging field of interoperability research has come up with a vast number of concepts and technical solutions. Among them are model-driven design of cross-organisational integration, ontology building and semantic reconciliation. However, until today, those technical interoperability solutions are not yet sufficiently linked to the business problems they address.

The aim of this paper is 
1. to systemise typical interoperability issues from a business perspective (described by Business Interoperability Profiles, BIP) and

2. to relate them to the appropriate interoperability solutions which may solve these issues.

This work extends previous interoperability research by linking the technical view on interoperability to business drivers and needs. The paper thereby suggests a business-oriented categorisation of interoperability solutions.

We start with the definition of interoperability from a technical and a business perspective in Section 2, followed by an overview of business interoperability issues as well as interoperability solutions in Section 3. We then present the categorisation of typical business interoperability issues into Business Interoperability Profiles (BIP). Finally, we present the mapping of the BIP to specific interoperability solutions which research has recently been suggesting. The categorisation and the interoperability solutions have been derived from our work in the ATHENA research project (http://www.athena-ip.org) and have been verified through additional projects carried out by the authors. We do not claim that the list of BIP or the technical solutions are complete. However, based on our experience from several industrial interoperability projects we believe that it covers a fairly large portion of issues and solutions.

\section{Underlying concepts}

\subsection{Defining Interoperability}

The definition of interoperability that underlies the ATHENA project is "the ability of two or more systems or components to exchange information and to use the information that has been exchanged" [1]. This definition relates to the technical aspects of interoperability by suggesting standards and solutions for presenting, collecting, exchanging, processing and transporting data.

From a business perspective, technical interoperability allows for seamlessly propagating and sharing information between partners. [15] define business interoperability as "the organisational and operational ability of an enterprise to cooperate with its business partners and to efficiently establish, conduct and develop IT-supported business relationships with the objective to create value.” As such, business interoperability extends the more technically focused notion of interoperability to cover organisational and operational aspects of setting up and running IT-supported relationships. It builds on the concept of networkability [17] which is a continuation of coordination theory and sees coordination as the management of relationships of dependence [12][20]. Among different issues which may arise on business level are the following:

- defining and formalising cooperation goals with business partners (e.g. by contracts and service level agreements),

- streamlining business processes across organisations in order to eliminate redundancies, and 
- deciding on the desired level of electronic interaction and the use of industry standards with business partners.

\subsection{Business Interoperability Issues}

Organisations which seek to electronically interact with their business partners typically need to establish higher levels of external coordination [13]. The "Business Interoperability Framework" [15] classifies the resulting interoperability issues into four categories and describes different interoperability levels (Fig. 1):

Management of External Relationships: Increasing levels of external collaboration require companies to systematically plan, implement and monitor their cooperation with external partners and to co-define cooperation targets (“cooperation management and targets").

Employee \& Culture: Tighter process integration requires business partners to cooperate in a climate of trust and confidence ("trust”).

Collaborative Business Processes: In B2B relationships, responsibilities of each partner are often unclear and activities are performed ad-hoc, which results in resource conflicts as well as coordination effort. Organisations become more interoperable if they collaborate based on a clear and well documented crossorganisational business process that is practical and reflects industry standards ("public process"). A key issue in aligning business processes lies in a mismatch of terminologies between different organisations ("business semantics").

Information systems: Electronic connections with business partners may facilitate the exchange of data or knowledge ("data integration") as well as automated coupling of processes ("process integration”). For both, interoperability is depending on the interaction types (human-machine, machine-machine). When setting up electronic links with business partners, companies often struggle with bilateral agreements e.g. on data formats and communication protocols. The lack of scalability to a broader number of business partners has so far hindered the diffusion of inter-organisational systems. A high connectivity is achieved by replacing individual connections (1:1) with m:n connections (“connectivity”).

When comparing different industries, it becomes evident that they are characterised by different levels of business interoperability (cf. Fig. 1). In the high-tech industry, the supply chain between Original Equipment Manufacturers (OEM), contractors and component manufacturers is tightly integrated. Companies like Cisco or HP adhere to process standards (e.g. RosettaNet) and use collaboration platforms (e.g. Viacore) which ease electronic collaboration with their business partners. In many other areas, e.g. in facility management, the fragmentation of the value chain and the size of the companies make it more difficult to establish similar IT-supported business relationships. These examples illustrate that the achievable level of business interoperability, i.e. the level with maximum value creation, depends on environmental factors as well as on the chosen cooperation strategy. As a consequence, we base our argumentation on Contingency Theory [9] and assume that the appropriate level of business interoperability has to "fit" external and internal factors, so-called contingencies. 
We derive the following contingencies as being relevant to business interoperability (cf. [15]):

- Cooperation model (internal contingency): The cooperation model includes a description and the number of cooperation partners, their relationships (e.g. competitors, supplier-buyer), the power distribution, roles and activities within the cooperation as well as the information, product and service flow between partners (i.e. the cooperation scenario).

- Industry environment (external contingency): The specific (industry) environment and its dynamics (cf. [8]) as well as its e-business maturity [10] highly influence the achievable level of business interoperability.

\begin{tabular}{|c|c|c|c|c|c|}
\hline \multirow[b]{2}{*}{ Interoperability issue } & \multicolumn{5}{|c|}{ Level of Business Interoperability } \\
\hline & $\begin{array}{c}5 \\
\text { (fully inter- } \\
\text { operable) }\end{array}$ & $\begin{array}{c}4 \\
\text { (qualified) }\end{array}$ & $\begin{array}{c}3 \\
\text { (moderate) }\end{array}$ & $\begin{array}{c}2 \\
\text { (minimum) }\end{array}$ & $\begin{array}{c}1 \\
\text { (none) }\end{array}$ \\
\hline \multicolumn{6}{|c|}{ Management of External Relationships } \\
\hline $\begin{array}{l}\text { Cooperation management } \\
\text { and targets }\end{array}$ & \multicolumn{3}{|c|}{$\begin{array}{l}\text { conscious partner } \\
\text { selection, co-defined } \\
\text { cooperation targets }\end{array}$} & \multicolumn{2}{|c|}{$\begin{array}{r}\text { Business relationships are } \\
\text { formed ad-hoc, partners } \\
\text { pursue individual targets }\end{array}$} \\
\hline \multicolumn{6}{|l|}{ Employes \& Culture } \\
\hline Trust & \multicolumn{3}{|c|}{$\begin{array}{l}\text { mutual sense of trust and } \\
\text { confidence }\end{array}$} & \multicolumn{2}{|c|}{$\begin{array}{l}\text { Low awareness of trust, } \\
\text { "them and us" attitude }\end{array}$} \\
\hline \multicolumn{6}{|c|}{ Collaborative Business Process } \\
\hline Public process & \multicolumn{3}{|c|}{$\begin{array}{l}\text { commonly accepted public } \\
\text { processes reflecting } \\
\text { industry or domain } \\
\text { standards }\end{array}$} & \multicolumn{2}{|c|}{$\begin{array}{r}\text { no awareness of the cross- } \\
\text { organizational business } \\
\text { process }\end{array}$} \\
\hline Business semantics & \multicolumn{3}{|c|}{$\begin{array}{l}\text { commonly accepted } \\
\text { business terminology } \\
\text { reflecting industry or } \\
\text { domain standards }\end{array}$} & \multicolumn{2}{|c|}{ proprietary semantics } \\
\hline \multicolumn{6}{|l|}{ Information Systems } \\
\hline $\begin{array}{l}\text { Interaction type } \\
\text { (process / data integration) }\end{array}$ & \multicolumn{3}{|c|}{\begin{tabular}{|l|} 
machine-machine \\
integration
\end{tabular}} & \multicolumn{2}{|c|}{$\begin{array}{r}\text { human-to-human } \\
\text { interaction }\end{array}$} \\
\hline Connectivity & \multicolumn{3}{|c|}{$\begin{array}{l}\text { B2B architecture with m:n- } \\
\text { connectivity }\end{array}$} & \multicolumn{2}{|c|}{$\begin{array}{r}\text { no electronic connections } \\
\text { established }\end{array}$} \\
\hline
\end{tabular}

Fig. 1. Categories of Business Interoperability and their Levels

\subsection{Technical Interoperability Solutions}

Recent research and technology development has led to a number of new technical solutions addressing interoperability problems. Major interoperability research streams come from enterprise modelling and model-driven development [16], semantic technologies such as ontology management systems or semantic reconciliation (e.g. [3]), service-oriented architectures (e.g. [2]) and a semiautomated support for modelling and executing cross-organisational business processes (e.g. [11]). These research streams address different aspects of interoperability and consequently can be distinguished according to the artefacts they are focussing on: business processes, services, information / data, and other aspects such as security, service-level agreements and contract handling. 
New concepts and technical solutions are emerging for solving interoperability issues related to these artefacts. Recent approaches to cross-organisational business process definition and implementation separate public and private views of the business processes spanning multiple organisations. Service-oriented solutions suggest the realisation of a service-oriented architecture combined with the use of Web Services as the technical basis for integrating heterogeneous software application. In the area of information/data concepts such as semantic reconciliation address aspects related to modelling and detailed specification of information that is exchanged between collaborating organisations. For the other aspects technical solutions come for instance from projects in the security and trust area or from research on virtual organisations (e.g. [19]).

Orthogonal to these artefacts, model-driven development [16] suggests that the building of an interoperability solution can be organised around a set of models, ranging from the overall enterprise perspective to the execution or code level. A formal underpinning for describing models in a set of meta-models facilitates meaningful integration and transformation among models, and is the basis for automation through tools:

Business Level (Computational Independent Model, CIM): This level represents the business view on a business relationship, reflecting strategic decisions on the competitive positioning of an enterprise as well as the organizational and process design.

Technical Level (Platform Independent Model, PIM): To achieve an executable interoperability solution, the business level models first have to be transformed into platform-independent models. Optimally, business level models are transformed into technical level models and enriched with more detailed information. However, the models on this level still abstract from the implementation platform.

Execution Level (Platform Specific Model, PSM): With the second transformation the technical level models are transformed to platform-specific execution level models. Platform-specific models are indispensable for the actual implementation of a system. These models are executed and make the interoperability solutions work.

\section{Deriving Business Interoperability Profiles (BIP)}

\subsection{Method of Work}

It is the aim of this paper to accomplish a business-oriented approach towards the implementation of technical interoperability solutions. We therefore identify typical, recurring Business Interoperability Issues and systemise them into a set of Business Interoperability Profiles (cf. Fig. 2, Step 2). This is based on various case studies that were conducted within and outside the ATHENA project (Step 1). At this stage we have identified seven Business Interoperability Profiles which we believe to cover a fairly large portion of issues. This grouping of Interoperability Issues leads us to the identification of a dedicated technical approach that is 
required to implement the desired level of business interoperability (Step 3). By knowing what needs to be done on a technical level, we can now determine general technical Interoperability Solutions that are applicable (Step 4).

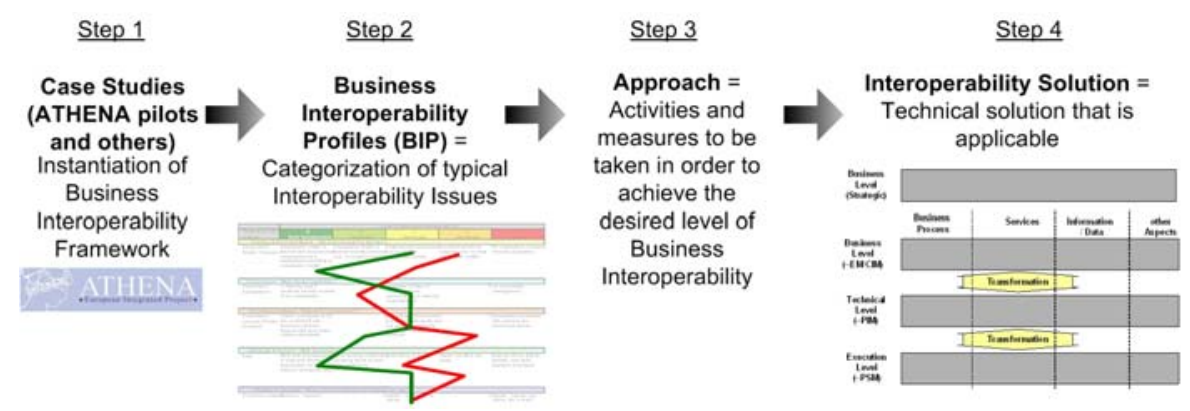

Fig. 2. Method of Work

All Business Interoperability Profiles and the related Interoperability Issues are explained in more detail in the next Section. For each profile we first describe the internal and external contingencies (cf. Fig. 3, column 3-4) before detailing the Interoperability Issues related to Management of External Relationships, Employee and Culture, Collaborative Business Processes and Information Systems (column 5-8). The textual descriptions are complemented by colours that depict the levels of business interoperability for each profile (cf. Section 2.2). The arrows provide an indication of possible improvements of interoperability levels when implementing the proposed solution. Column 9 ("Approach") explains the design and implementation approach that is required to solve the related Interoperability Issues. The next columns then list the applicable interoperability solutions, the modelling levels involved and the artefacts to be considered. The classification of solutions into the above defined artefacts and modelling levels, help us to specify more precisely which interoperability solutions have to be implemented and which type of models have to be generated during design and development.

\subsection{Business Interoperability Profiles - Description}

In the following, we provide a detailed description of each Business Interoperability Profile (BIP). These profiles represent clusters of typical business interoperability issues and the associated solutions. Fig. 3 provides the consolidated overview of all BIP.

BIP 1: Ecosystem Design \& Cooperation Strategy

BIP 1 characterises organisations which do not systematically manage their external relationships. Since they typically have not defined their cooperation model, they are unaware of collaborative business processes and have not yet invested in electronic connectivity with business partners. This business interoperability profile is more frequent in industries which are highly fragmented and are characterised by low e-business maturity, e.g. facility management. 
In order to become more interoperable, companies have to identify relevant partners, i.e. their ecosystem, and define their cooperation strategy. Enterprise modelling supports stakeholders such as business and strategy experts in describing and visualising their value network and their business model. Main modelling elements are organisations with their input and output relationships (physical goods, financial and information flows). Popular modelling tools are for example ARIS [7], GraiTools, Mo2Go [14] or METIS. Since different organisations may use different tools and techniques for enterprise modelling, meta-model based transformation and exchange of models facilitates interoperability. The translation of the top-level (strategic) cooperation strategy into specific collaborative processes and system architectures is subject of subsequent project phases.

\section{BIP 2: Design of "Public Process"}

BIP 2 characterises organisations which have defined their cooperation model, and as a consequence need to re-organise the way they are collaborating with their business partners. They need to identify the affected cross-organisational business processes and have to clarify the public process. The latter can be defined either by starting a consensus building approach with business partners or by one partner defining the process for all partners. In industries with equal power distribution the first approach is prevailing, whereas in hierarchical business relationships the focal partner (or network orchestrator) will more likely define the process.

The definition of and the consensus building on public processes is supported by enterprise modelling tools (similar to the tools mentioned in BIP 1) as well as specific business process modelling languages, concepts and tools, such as ARIS Event-driven Process Chains, UML activity diagrams or BPMN. Business experts use them to detail the interaction between business partners and to agree on a common public business process. Furthermore global modelling languages should be used to define high level service interaction models. The design of further artefacts such as detailed service descriptions and information/data is not subject of this BIP, but will be covered later (BIP 4 and 5).

BIP 3: Coupling with Existing "Public Process"

BIP 3 characterises organisations which have defined their cooperation model and seek to adhere to an already existing public process. A high-tech company which seeks to interact with their business partners using RosettaNet PIPs may serve as an example. BIP 3 requires the existence of a documented public process which may have either been defined by other organisation(s), acting as focal companies or network orchestrators, or a standardisation body. It is consequently more frequent in an environment with a medium e-business maturity.

To adhere to the public process, companies may have to re-organise and change their internal processes. Technical solutions to support these changes can be from the area of enterprise and business process modelling [16]. Recent extensions of business process modelling provide concepts for modelling public and view processes and map them to internal processes. Tool support for public-viewinternal process mapping is for example offered in Maestro and Mo2Go NG. To design internal processes and to link them with a public process, it is sufficient to consider the business process models on a business level without consideration of 
technical details such as message exchange or service interfaces. Involved stakeholders are business experts that translate cooperation strategy and business model into a process design.

\section{BIP 4: Definition of Business Semantics}

BIP 4 addresses the issue of defining a common terminology and understanding of the information to be exchanged between business partners. Whereas standardisation initiatives have produced data dictionaries and information models for specific domains (e.g. supply chain management), a comparable level of shared business semantics is still lacking across different industries or for more complex collaboration scenarios (e.g. in the area of product development and post-sales).

Common business semantics are a prerequisite to implement data-based as well as process-based connectivity and can be achieved through information modelling. BIP 4 typically focuses on the terminology and meaning of the information exchanged in the specific context and does not yet take into account the data structures which have been implemented in different information systems. Business experts and IT architects are involved in defining a common ontology or a common vocabulary for the specific domain. They are supported by respective methodologies for ontology definition as well as ontology authoring tools (e.g. ATHOS [6] or Protégé). Semantic annotation can be used for formal knowledge representation.

\section{BIP 5: Design of Services and Business Documents}

BIP 5 relates to the design of services and business documents which are the basis for electronic integration. Depending on the focus on either process or data integration, it requires that a public process and/or common business semantics have been established. This situation is frequent in industries which are increasingly moving towards networked business models and have a high ebusiness maturity. Alike the design of a public process, design of services and business documents can either emerge as result of a consensus building activity or be defined by the focal company or network orchestrator.

Definition of business documents is supported by modelling tools that support e.g. a component-based modelling of business documents. To define services and service interfaces, technical specifications such as WSDL (Web Service Definition Language) can be used. Technical staff such as IT architects is necessary to actually create the services and data models using methods and tools for service specification (XMLSpy, Johnson [5], etc.) and tools that support a definition and mapping of business documents (Maestro, XML Editing Tools, etc.). The transformation to models for a particular execution platform is subject to later project phases.

\section{BIP 6: Implementation of Process Integration}

This BIP focuses on the electronic coupling of business processes with the target to move from human-human or human-machine interaction to machine-machine integration. Basis for achieving higher levels of electronic process integration is a common understanding of the public process, the availability of service definitions as well as the existence of common business semantics. This business 
interoperability profile typically is found in business environments with high ebusiness maturity, e.g. the retail or the automotive industry.

\begin{tabular}{|c|c|c|c|c|c|c|c|}
\hline No & \begin{tabular}{|c|} 
Business \\
Interoper- \\
ability Profile \\
(BIP)
\end{tabular} & \begin{tabular}{|c} 
Cooperation \\
Model (Internal \\
Contingency)
\end{tabular} & $\begin{array}{c}\text { External } \\
\text { Contingencies }\end{array}$ & $\begin{array}{c}\text { Management of } \\
\text { External } \\
\text { Relationships }\end{array}$ & $\begin{array}{l}\text { Employee \& } \\
\text { Culture }\end{array}$ & $\begin{array}{c}\text { Collaborative Business } \\
\text { Process }\end{array}$ & Information Systems \\
\hline \multirow[t]{4}{*}{1} & \multirow[t]{4}{*}{\begin{tabular}{|l|} 
Ecosystem \\
design \& \\
cooperation \\
strategy
\end{tabular}} & \multirow[t]{4}{*}{$\begin{array}{l}\text { Cooperation } \\
\text { model not defined }\end{array}$} & \multirow[t]{4}{*}{$\begin{array}{l}\text { Low to medium e- } \\
\text { business maturity, } \\
\text { usually fragmented } \\
\text { industries }\end{array}$} & \multirow[t]{3}{*}{$\begin{array}{l}\text { Business } \\
\text { relationships are } \\
\text { formed ad-hoc }\end{array}$} & \multirow[t]{3}{*}{\begin{tabular}{|l} 
Low awareness of \\
external partners
\end{tabular}} & $\begin{array}{l}\text { Public process: No } \\
\text { awareness of } \\
\text { collaborative business } \\
\text { processes }\end{array}$ & $\begin{array}{l}\text { Human-to-human } \\
\text { interaction }\end{array}$ \\
\hline & & & & & & & \\
\hline & & & & & & $\begin{array}{l}\text { Proprietery business } \\
\text { semantics }\end{array}$ & $\begin{array}{l}\text { No electronic } \\
\text { connectivity }\end{array}$ \\
\hline & & & & 4 & 4 & & \\
\hline \multirow[t]{4}{*}{2} & \multirow[t]{4}{*}{\begin{tabular}{|l|} 
Design of \\
public process
\end{tabular}} & \multirow[t]{4}{*}{$\begin{array}{l}\text { Cooperation } \\
\text { scenario and } \\
\text { targets defined }\end{array}$} & \multirow[t]{4}{*}{$\begin{array}{l}\text { Low e-business } \\
\text { maturity, usually } \\
\text { fragmented } \\
\text { industries }\end{array}$} & \multirow{4}{*}{\begin{tabular}{|l} 
Cooperation is \\
managed, \\
cooperation targets \\
are defined \\
individually by \\
partners
\end{tabular}} & \multirow[t]{3}{*}{\begin{tabular}{|l}
$\begin{array}{l}\text { Basic level of trust } \\
\text { between partners }\end{array}$ \\
\end{tabular}} & $\begin{array}{l}\text { Public process: No } \\
\text { awareness of } \\
\text { collaborative business } \\
\text { processes }\end{array}$ & $\begin{array}{l}\text { not relevant, usually } \\
\text { human-to-human } \\
\text { interaction }\end{array}$ \\
\hline & & & & & & \begin{tabular}{|l|l|l|l|} 
& & 4 & \\
\end{tabular} & \\
\hline & & & & & & $\begin{array}{l}\text { Proprietery business } \\
\text { semantics }\end{array}$ & $\begin{array}{l}\text { Connectivity: not } \\
\text { relevant, usually } 1: 1 \\
\text { relationships } \\
\end{array}$ \\
\hline & & & & & & 4 & \\
\hline \multirow[t]{4}{*}{3} & \multirow[t]{4}{*}{\begin{tabular}{|l|} 
Coupling with \\
existing public \\
process
\end{tabular}} & \multirow[t]{4}{*}{$\begin{array}{l}\text { Cooperation } \\
\text { scenario and } \\
\text { targets defined }\end{array}$} & \multirow{4}{*}{$\begin{array}{l}\text { Existence of public } \\
\text { process and } \\
\text { business semantics, } \\
\text { medium e-business } \\
\text { maturity }\end{array}$} & \multirow{4}{*}{$\begin{array}{l}\text { Cooperation is } \\
\text { actively managed, } \\
\text { cooperation targets } \\
\text { are shared }\end{array}$} & \multirow[t]{3}{*}{$\begin{array}{l}\text { Partners trust each } \\
\text { other and invest in } \\
\text { good working } \\
\text { relationships }\end{array}$} & $\begin{array}{l}\text { Public process: } \\
\text { individual business } \\
\text { processes are not } \\
\text { aligned }\end{array}$ & $\begin{array}{l}\text { Not relevant, usually } \\
\text { human-to-human } \\
\text { interaction }\end{array}$ \\
\hline & & & & & & \begin{tabular}{|l|l|l|}
4 &
\end{tabular} & \\
\hline & & & & & & $\begin{array}{l}\text { Business semantics are } \\
\text { defined on a proprietary } \\
\text { base or bilaterally }\end{array}$ & $\begin{array}{l}\text { Connectivity: not } \\
\text { relevant, usually 1:1 } \\
\text { relationships }\end{array}$ \\
\hline & & & & & & 4 & \\
\hline \multirow[t]{4}{*}{4} & \multirow[t]{4}{*}{$\begin{array}{l}\text { Definition of } \\
\text { business } \\
\text { semantics }\end{array}$} & $\begin{array}{l}\text { Cooperation } \\
\text { scenario and } \\
\text { targets defined, } \\
\text { high cooperation }\end{array}$ & $\begin{array}{l}\text { Low e-business } \\
\text { maturity, usually } \\
\text { fragmented } \\
\text { industries }\end{array}$ & $\begin{array}{l}\text { Cooperation is } \\
\text { managed, } \\
\text { cooperation targets } \\
\text { are defined }\end{array}$ & \begin{tabular}{|l} 
Basic level of trust \\
between partners
\end{tabular} & \begin{tabular}{|l}
$\begin{array}{l}\text { Public process is not } \\
\text { relevant (usually low to } \\
\text { medium levels) }\end{array}$ \\
\end{tabular} & $\begin{array}{l}\text { not relevant, usually } \\
\text { human-to-human } \\
\text { interaction }\end{array}$ \\
\hline & & specincity & & Inavideually by & & & \\
\hline & & & & & & $\begin{array}{l}\text { Proprietery business } \\
\text { semantics }\end{array}$ & $\begin{array}{l}\text { Connectivity: not } \\
\text { relevant, usually } 1: 1 \\
\text { relationships }\end{array}$ \\
\hline & & & & & & 4 & \\
\hline 5 & $\begin{array}{l}\text { Design of } \\
\text { services and } \\
\text { business }\end{array}$ & \begin{tabular}{|l} 
Cooperation \\
scenario and \\
targets defined
\end{tabular} & $\begin{array}{l}\text { Public process and } \\
\text { business semantics } \\
\text { defined, medium e- }\end{array}$ & $\begin{array}{l}\text { Cooperation is } \\
\text { managed, } \\
\text { cooperation targets }\end{array}$ & $\begin{array}{l}\text { Basic level of trust } \\
\text { between partners }\end{array}$ & $\begin{array}{l}\text { Individual business } \\
\text { processes are aligned by } \\
\text { a public process }\end{array}$ & $\begin{array}{l}\text { Human-to-machine } \\
\text { interaction }\end{array}$ \\
\hline & documents & & business maturity & are defined & & & \begin{tabular}{l|l|l|}
4 & \\
\end{tabular} \\
\hline & & & & $\begin{array}{l}\text { individually by } \\
\text { partners }\end{array}$ & & \begin{tabular}{|l} 
Commonly accepted \\
business semantics \\
employed
\end{tabular} & \begin{tabular}{|l|} 
Connectivity: $1: 1$ or $1: n$ \\
relationships
\end{tabular} \\
\hline & & & & & & & 4 \\
\hline 6 & \begin{tabular}{|l}
$\begin{array}{l}\text { Implemen- } \\
\text { tation of } \\
\text { process }\end{array}$ \\
\end{tabular} & \begin{tabular}{|l|} 
Cooperation \\
scenario and \\
targets defined
\end{tabular} & \begin{tabular}{|l|} 
Public process, \\
business semantics, \\
services and
\end{tabular} & $\begin{array}{l}\text { Cooperation is } \\
\text { actively managed, } \\
\text { cooperation targets }\end{array}$ & $\begin{array}{l}\text { Partners trust each } \\
\text { other and invest in } \\
\text { good working }\end{array}$ & \begin{tabular}{|l|} 
Individual business \\
processes are aligned by \\
a public process
\end{tabular} & \begin{tabular}{|l} 
Human-to-machine \\
interaction, process \\
integration
\end{tabular} \\
\hline & integration & & business documents & are shared & relationships & & \begin{tabular}{|l|l|l|}
4 & & \\
\end{tabular} \\
\hline & & & $\begin{array}{l}\text { defined, medium to } \\
\text { high e-business } \\
\text { maturity }\end{array}$ & & & $\begin{array}{l}\text { Commonly accepted } \\
\text { business semantics } \\
\text { employed }\end{array}$ & \begin{tabular}{|l|}
$\begin{array}{l}\text { Connectivity: } 1: 1 \text { or } 1: n \\
\text { relationships }\end{array}$ \\
\end{tabular} \\
\hline & & & & & & & 4 \\
\hline 7 & \begin{tabular}{|l|} 
Implemen- \\
tation of data \\
integration
\end{tabular} & $\begin{array}{l}\text { Cooperation } \\
\text { scenario and } \\
\text { targets defined }\end{array}$ & \begin{tabular}{|l} 
Existence of \\
services and \\
business \\
documents, medium
\end{tabular} & $\begin{array}{l}\text { Cooperation is } \\
\text { managed, } \\
\text { cooperation targets } \\
\text { are defined }\end{array}$ & \begin{tabular}{|l} 
Basic level of trust \\
between partners
\end{tabular} & \begin{tabular}{|l}
$\begin{array}{l}\text { Public process is not } \\
\text { relevant (usually low to } \\
\text { medium levels) }\end{array}$ \\
\end{tabular} & \begin{tabular}{|l|} 
Human-to-machine inter \\
action, data integration
\end{tabular} \\
\hline & & & to high e-business & individually by & & & 4 \\
\hline & & & maturity & partners & & $\begin{array}{l}\text { Commonly accepted } \\
\text { business semantics } \\
\text { employed }\end{array}$ & $\begin{array}{l}\text { Connectivity: } 1: 1 \text { or } 1: n \\
\text { relationships }\end{array}$ \\
\hline & & & & & & & \begin{tabular}{l|l|}
4 \\
\end{tabular} \\
\hline
\end{tabular}

Fig. 3. Business Interoperability Profiles - Table Overview (Part I) 


\begin{tabular}{|c|c|c|c|c|c|}
\hline No & $\begin{array}{c}\text { Business } \\
\text { Interoper- } \\
\text { ability Profile } \\
\text { (BIP) }\end{array}$ & Approach & Technical Interoperability Solution & $\begin{array}{c}\text { Modelling and } \\
\text { specification level }\end{array}$ & Main artefacts \\
\hline 1 & \begin{tabular}{|l|} 
Ecosystem \\
design \& \\
cooperation \\
strategy
\end{tabular} & \begin{tabular}{|l} 
Design ecosystem, define and \\
document cooperation strategy, \\
exchange documentation between \\
partners
\end{tabular} & $\begin{array}{l}\text { Methods and tools for enterprise } \\
\text { modelling that support modelling of value } \\
\text { network and business model (e.g. ARIS, } \\
\text { GraiTools, Mo2Go, METIS), exchange of } \\
\text { enterprise models (e.g. using POP* meta- } \\
\text { model) }\end{array}$ & $\begin{array}{l}\text { Business level } \\
\text { (Strategy) }\end{array}$ & $\begin{array}{l}\text { Organizations and } \\
\text { roles, input-output } \\
\text { relationships } \\
\text { (information, physical } \\
\text { goods, ...) }\end{array}$ \\
\hline 2 & $\begin{array}{l}\text { Design of } \\
\text { public process }\end{array}$ & Commonly define public process & $\begin{array}{l}\text { Process modelling methods and Tools } \\
\text { specificly targeted at cross-organisational } \\
\text { processes (e.g. ARIS EPC, BPMN, } \\
\text { GraiTools, Maestro, METIS, MoGo); } \\
\text { Exchange of business process models }\end{array}$ & $\begin{array}{l}\text { Business level } \\
\text { (Organization and } \\
\text { Processes) }\end{array}$ & $\begin{array}{l}\text { Public processes / } \\
\text { activities }\end{array}$ \\
\hline 3 & $\begin{array}{l}\text { Coupling with } \\
\text { existing public } \\
\text { process }\end{array}$ & \begin{tabular}{|l|} 
Link private process to public \\
processes: Model private and view \\
processes, map private process to \\
public process; if necessary re-organise \\
private processes
\end{tabular} & $\begin{array}{l}\text { Process modelling methods and tools that } \\
\text { are capable of supporting the view } \\
\text { approach and allow for a linkage of } \\
\text { private, view and public processes (ARIS } \\
\text { EPC, Mo2Go NG, BPMN, Maestro, ...); } \\
\text { Model-transformation of business process } \\
\text { modelling tools; Global modelling } \\
\text { solution }\end{array}$ & \begin{tabular}{|l} 
Business level \\
(Organization and \\
Processes)
\end{tabular} & \begin{tabular}{|l} 
Public and private \\
processes (views) / \\
activities
\end{tabular} \\
\hline 4 & $\begin{array}{l}\text { Definition of } \\
\text { business } \\
\text { semantics }\end{array}$ & $\begin{array}{l}\text { Describe common vocabulary, Define } \\
\text { ontology }\end{array}$ & $\begin{array}{l}\text { Ontology definition methods and ontology } \\
\text { authoring tools (e.g. ATHOS, Protégé); } \\
\text { Semantic annotation (e.g. A*) }\end{array}$ & $\begin{array}{l}\text { Business level } \\
\text { (Information and } \\
\text { Knowledge) }\end{array}$ & \begin{tabular}{|l} 
Information / \\
knowledge
\end{tabular} \\
\hline 5 & \begin{tabular}{|l} 
Design of \\
services and \\
business \\
documents
\end{tabular} & $\begin{array}{l}\text { Model business documents (high-level } \\
\text { and components), define services and } \\
\text { service interfaces }\end{array}$ & $\begin{array}{l}\text { Methods and tools for service } \\
\text { specification (e.g. XMLSpy, Johnson); } \\
\text { Methods and tools that support a } \\
\text { definition and mapping of business } \\
\text { documents (e.g. Maestro, XML Editing } \\
\text { Tools) }\end{array}$ & Technical level & \begin{tabular}{|l} 
Services, information \\
data
\end{tabular} \\
\hline 6 & $\begin{array}{l}\text { Implemen- } \\
\text { tation of } \\
\text { process } \\
\text { integration }\end{array}$ & \begin{tabular}{|l|} 
Model private and view processes on \\
technical level; map private process to \\
public process on technical level; \\
create services; connect processes with \\
services; create message exchange; \\
define and deploy on execution \\
infrastructure
\end{tabular} & $\begin{array}{l}\text { Methods and tools for model-driven } \\
\text { developement e.g. PIM4SOA); Methods } \\
\text { and tools for technical speficification of } \\
\text { services and workflows (e.g. Maestro, } \\
\text { Gabriel); Respective execution } \\
\text { infrastructure: SOA (e.g. Johnson), agents } \\
\text { (e.g. JACK), peer-to-peer (e.g. WS } \\
\text { Execution Engine) }\end{array}$ & \begin{tabular}{|l|} 
Technical and \\
execution level
\end{tabular} & $\begin{array}{l}\text { Workflows, services, } \\
\text { information / data }\end{array}$ \\
\hline 7 & $\begin{array}{l}\text { Implemen- } \\
\text { tation of data } \\
\text { integration }\end{array}$ & $\begin{array}{l}\text { Define source and target data format; } \\
\text { define data transformation and } \\
\text { mapping; define and deploy on } \\
\text { execution infrastructure }\end{array}$ & $\begin{array}{l}\text { Mapping methods and tools (e.g. STEP } \\
\text { Mapper); Semantic annotation and } \\
\text { runtime reconciliation (e.g. A*, ARGOS, } \\
\text { ATHOS, Semaphore) }\end{array}$ & $\begin{array}{l}\text { Technical and } \\
\text { execution level }\end{array}$ & $\begin{array}{l}\text { Services, information } \\
\text { data }\end{array}$ \\
\hline
\end{tabular}

Fig. 4. Business Interoperability Profiles - Table Overview (Part II) 
To achieve the coupling of the processes, IT architects first transform the business level models of processes to a platform-independent technical representation. On this level they enrich the models of private and view processes with more detailed information about the services to call and the messages to exchange. They also link the private process models of the partners to a technical level model of the public process. Model-driven development (e.g. supported by PIM4SOA [18]) and tools for technical specification of services and workflows (such as Maestro or Gabriel [4]) increase interoperability at this stage. To actually enact the processes, IT architects and IT administrators have to define the desired execution infrastructure, e.g. service-oriented architectures, agents or peer-to-peer. They then transform the technical level model to execution level models and deploy them on the selected execution infrastructure.

\section{BIP 7: Implementation of Data Integration}

BIP 7 relates to the electronic exchange of data in a machine-readable format. It requires common business semantics to be in place. A public process is not a prerequisite since this business interoperability profile may also relate to knowledge-oriented scenarios with an unstructured interaction.

To achieve machine-readable data exchange, IT architects define source and target data formats as well as the transformations between them (using e.g. STEP Mapper). To implement the transformation, an execution infrastructure is identified and the transformations are deployed. This can be supported for instance by functionality to export component-based document models to XML. Semantic annotation and runtime reconciliation facilitate model-based (instead of implementation) transformation. If the data transformation relates to message exchange in a common business process, the respective links between data and process steps have to be maintained by the process execution platform.

\section{Summary and Future Research}

In order to systemise the broad range of emerging interoperability concepts and tools, this paper shows that the interoperability solutions address different business issues and stakeholders. It suggests a more differentiated view on interoperability by identifying business interoperability issues and linking them to technical interoperability solutions. Fig. 3 summarises the business interoperability profiles and the associated interoperability solutions. In addition, it lists the approach that should be taken, the stakeholders involved and the artefacts that have to be considered. Mapping the Business Interoperability Profiles to the interoperability solution schema allows organisations to select the interoperability solutions which best fit their interoperability issues. The Profiles also help researchers to position their research results in a broader context.

So far, Business Interoperability Profiles and their mapping to the interoperability concepts and solutions have been tested in a limited number of case studies. Depending on the existing level of business interoperability, these cases started with different BIPs and consecutively applied a set of three to five 
BIPs. Further evaluation and completion of categorisation of business interoperability issues and BIP is subject to future research.

Given the background from the ATHENA project, the BIPs defined in this paper have a strong focus on the modelling and implementation of business processes at different levels of abstraction. Business Processes usually imply an information exchange via messages as well as a mostly sequential order of process steps. In addition, we can imagine collaboration scenarios that consist of a concurrent set of operations (for instance, performed by different actors or software applications) each performing on the same object. The BIP should be extended by so called knowledge based interactions.

\section{Acknowledgements}

The work published in this paper is (partly) funded by the E.C. through the ATHENA IP. It does not represent the view of E.C. or the ATHENA consortium, and authors are solely responsible for the paper's content.

\section{References}

[1] ATHENA, (2005) ATHENA European Integrated Project, 23.09.2005.

[2] ATHENA, (2006) Deliverables from project A5. http://www.athena-ip.org

[3] ATHENA, (2006) Deliverables from project A3. http://www.athena-ip.org

[4] ATHENA, (2006) Gabriel, ATHENA Deliverable. http://www.athena-ip.org

[5] ATHENA, (2006) Johnson, ATHENA Deliverable. http://www.athena-ip.org

[6] ATHENA, (2006) ATHOS, ATHENA Deliverable. http://www.athena-ip.org

[7] IDS Scheer AG, (2006) ARIS Platform http://www.ids-scheer.de

[8] Daft RL, (2004) Organization Theory and Design, Thomson South-Western, Manson

[9] Donaldson L, (2001) The Contingency Theory of Organizations, Sage Publications, Thousand Oaks, CA

[10] e-Business Watch, (2005) The European e-Business Report - 2005 edition. Available at http://www.ebusiness-watch.org/resources/documents/eBusiness-Report-2005.pdf

[11] Greiner U, Lippe S, Kahl T, Ziemann J, Jäkel FW, (2006) Designing and Implementing Cross-Organizational Business Processes - Description and Application of a Modelling Framework. Proc. of I-ESA 2006

[12] Malone TW, Crowston K, (1994) The Interdisciplinary Study of Coordination. ACM Computing, Surveys 26 (1):87-119

[13] McAfee A, (2005) Will Web Services Really Transform Collaboration? MIT Sloan Management, Review 46(2):78-84

[14] MooGo. Fraunhofer AG. http://www.moogo.de/

[15] Legner C, Wende K, (2006) Towards an Excellence Framework for Business Interoperability. 19th Bled eConference eValues

[16] OMG, MDA Guide Version 1.0.1, (2003) Available at http://www.omg.org/docs/omg/03-06-01

[17] Österle H, Fleisch E, Alt R, (2001) Business Networking: Shaping Collaboration Between Enterprises, Springer, Berlin et al.

[18] ATHENA consortium, (2006) PIM4SOA Available at http://pim4soa.sourceforge.net/index.html

[19] TrustCom project, (2006) http://www.eu-trustcom.com

[20] Wigand RT, Picot A, Reichwald R, (1997) Information, Organization and Management: Expanding Markets and Corporate Boundaries, John Wiley \& Sons, 